\title{
ПОТЕНЦИАЛ ИНФЛЯЦИИ КРИПТОВАЛЮТЫ С ТОЧКИ ЗРЕНИЯ ПРАВА
}

\author{
(c) 2018 Коржова Ирина Вадимовна \\ магистрант юридического факультета \\ Московского государственного университета им. М.В. Ломоносова \\ трехкратный лауреат премии Президента Российской Федерации \\ по поддержке талантливой молодежи \\ E-mail: irina140497@yandex.ru \\ (C) 2018 Хан Николай Александрович \\ кандидат исторических наук \\ член ассоциаций и общества экономической и социальной истории СГА, Великобритания, Канада \\ ООО «Команда комплексных экспедиционных разработок» \\ 108811, Москва, Поселение Внуковское, ул. Бориса Пастернака, д. 17 \\ E-mail:kh-niko@mail.ru
}

В настоящей статье исследуется потенциал криптовалют с точки зрения инфляции. Рассматриваются два типа криптовалют с майнингом на основе собственного алгоритма: 1) криптовалюты, у которых эмиссия ограничена; 2) криптовалюты, у которых эмиссия не ограничена. Анализируются процессы увеличения как числа этих валют, так и числа их эмитентов.

Ключевые слова: криптовалюты, Bitcoin, инфляция, проблемы правовых режимов, законодательство, правопреемство.

Криптовалюта - уникальный феномен, технические особенности которого существенным образом предопределяют экономические и юридические особенности. Криптовалюта с технической точки зрения - математический код, обращающийся в системе распределенного реестра - учетной записи, подтверждающей наличие криптовалюты.

В денежном обороте криптовалюты смогли бы ускорить, удешевить и значительно упростить расчеты, исключив из них традиционные финансовые институты.

Криптовалюта обладает следующими преимуществами, обусловленными архитектурными особенностями публичного распределенного реестра:

1) отсутствие необходимости в посредниках, ведущих счета, и в посредниках для осуществления платежей между отправителем и получателем средств;

2) независимость от человеческого фактора, при совершении транзакций не требуется доверять эмитенту или органам, осуществляющим финансовый мониторинг и надзор;

3) безопасность, надежность, прозрачность расчетов, возможность публичного аудита достоверности базы данных [1];

4) защищенность и невзламываемость опе-

раций;

5) минимизация транзакционных издержек, в том числе возможность трансграничных переводов с минимальными комиссиями.

Предметом исследования настоящей работы является потенциал инфляции криптовалют, майнинг которых производится на основе собственного алгоритма.

Существует 2 типа криптовалют с майнингом на основе собственного алгоритма, которые необходимо рассмотреть с точки зрения инфляции:

1) криптовалюты, у которых эмиссия ограничена;

2) криптовалюты, у которых эмиссия не ограничена.

Разработчики большинства криптовалют стремятся ограничить их эмиссию. Хрестоматийным примером криптовалюты с ограниченной эмиссией является классический Bitcoin. Bitcoin (BTC) - криптовалюта с самой высокой капитализацией. Появилась в 2009 году по цене менее одного цента. Согласно подсчетам максимальное число биткоинов составит 21 млн. монет. Количество выпущенных биткоинов растет с заранее заданной скоростью, в отличие от государственных денег, которые печатает правительство по своему усмотрению. Появление 
новых монет должно закончиться к 2140 году. Таймер обратного отсчета окончания эмиссии биткоина показан на рис. 1 [2].

Иными примерами криптовалют с ограниченной эмиссией являются: Bitcoin Cash (21 млн. ВСН), Litecoin (84 млн. LTC), EOS (1 млрд.), Cardano (45 млрд. ADA), NEO (100 млн.), IOTA (2,77 млрд. MIOTA), DASH (18,9 млн.).

Размножение или клонирование алгоритмов криптовалюты приводит к тому, что происходит увеличение как числа этих валют, так и числа их эмитентов. Необходимо учитывать и то обстоятельство, что новые криптовалюты в силу особенностей изменённого алгоритма могут быть «напечатаны» в неограниченном количестве. Примерами криптовалют, эмитируемых «без ограничений», являются следующие: Ethereum (ETH), Monero (XMR), Tether (USDT), LISK (LSK), Siacoin (SC), Dogecoin (DOGE), Peercoin (PPC).

Рассмотрим инфляционное положение криптовалюты Bitcoin, которая, как известно, привязана к доллару США. Любой финансист должен сказать, что доллар США котируется на основе стоимости корзины из шести валют индекса USDX, на дату 08112018 составляет 96,03 в месячном диапазоне 90-102 [3]. Поэтому становится ли дороже Bitcoin или дешевле по отно- шению к другим валютам обусловлено именно котировкой доллара (рис. 2).

Доллар США, как известно, подвержен собственной инфляции, таргетирование которой осуществляет Федеральный резерв США и составляет в настоящее время 2,3\% (рис.3) [4].

В феврале 2018 года курс Bitcoin подскочил до 20 тысяч долларов (рис. 4).

Пик цены этой криптовалюты не сделал доллар слабее, на что важно обратить внимание, а вызвал спекулятивный спрос, подстегиваемый не столько ажиотажным, сколько медийным интересом. Однако отсутствие покупательной способности или силы криптовалюты и непризнание ее в качестве платежного средства мировыми центральными регуляторами привело к тому, что курс его обрушился до \$6445 за монету и соответствует нынешнему состоянию числа «напечатанных» монет и количеству долларов, вложенных в это число.

Количество биткоинов в обращении по состоянию на 01.10.2018 г. составляет 4154263 экз. из 16845738 «напечатанных», согласно источнику [5]. Однако для темы статьи важно то обстоятельство, что 99\% криптомонет будет выпущено к 2036 г. и, понятно, что никто не будет ждать окончания периода его эмиссионного суще-

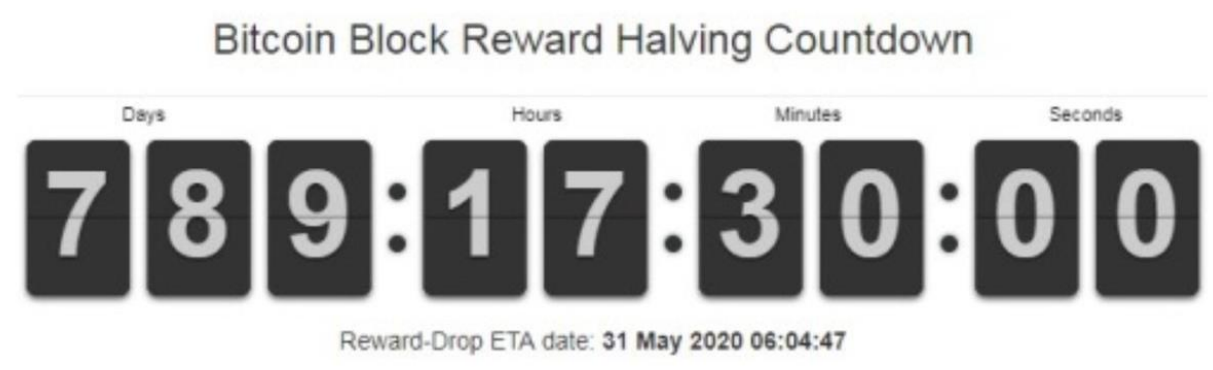

Puc. 1.

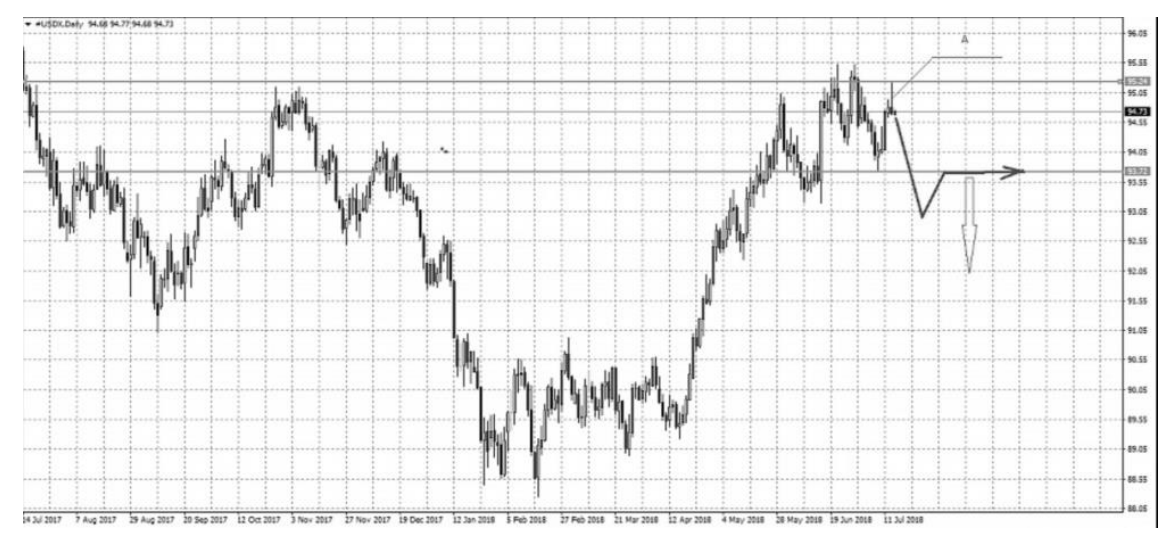

Puc. 2. 


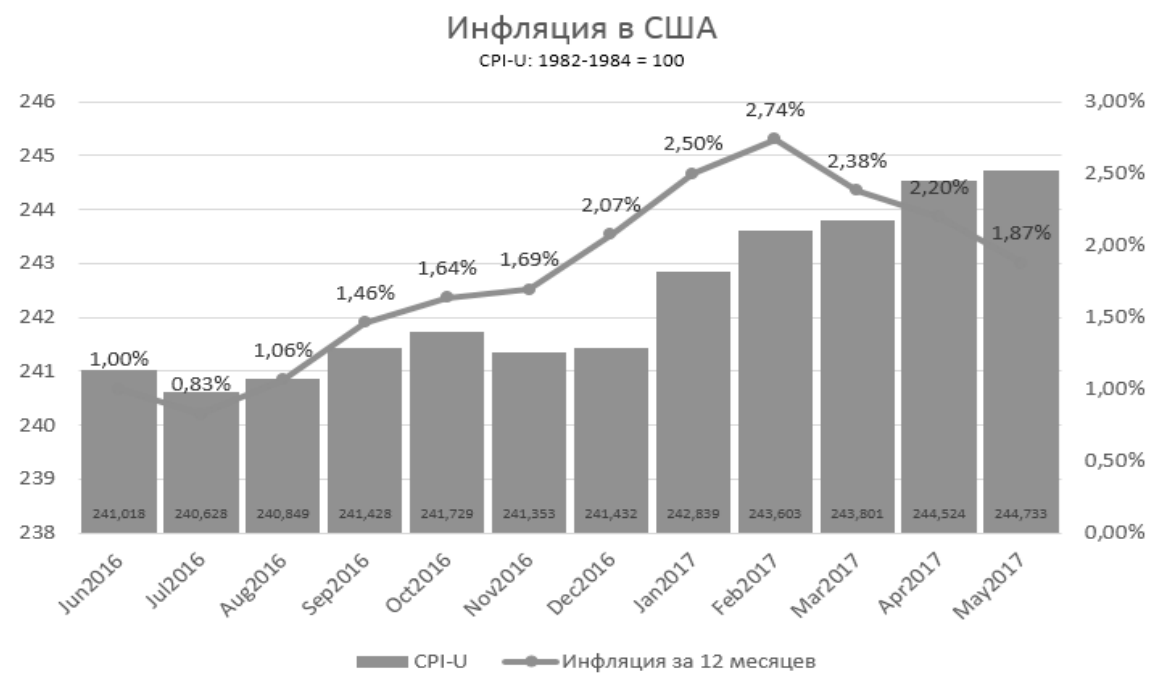

Рис. 3. График инфляции доллара США

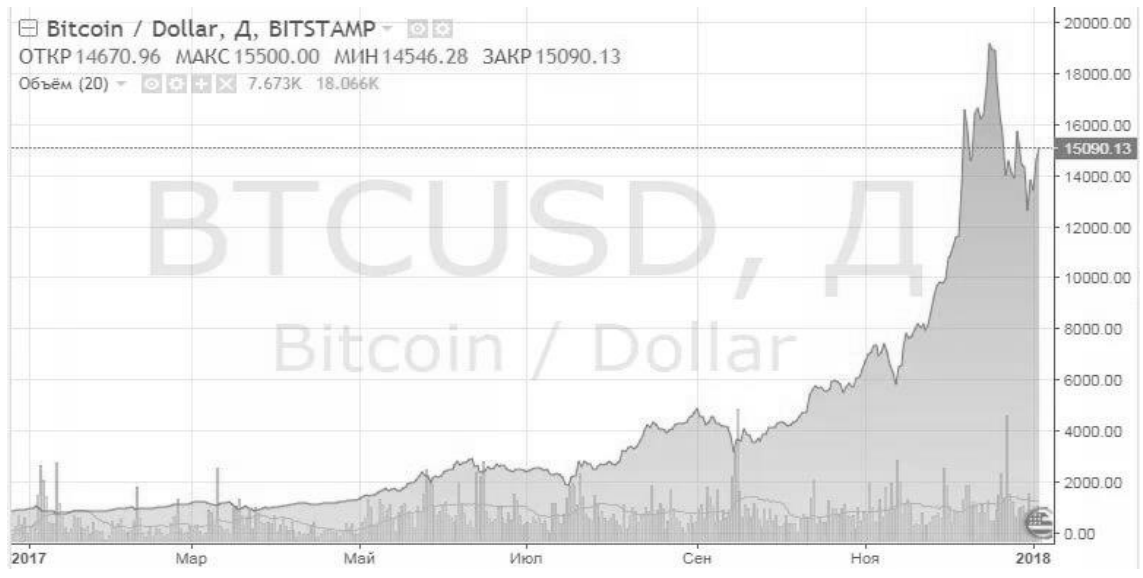

Puc. 4. График динамики курса Bitcoin к доллару США (2017-2018 гг.)

ствования, заканчивающегося в 2140 г. Более того, после «распечатки» 99,9х108 биткоинов дальнейший майнинг потеряет экономический смысл, однако престижная ценность от этого не уменьшится. Вместе с тем, падение числа монет любой криптовалюты есть регрессия, темп которой может быть изучен посредством универсальной формулы с выведением коэффициента падения; психологическая природа падения связана с особенностью человеческого бытия.

Однако последнюю монету, заданную алгоритмом создателей биткоина, нельзя будет положить на полку или поместить в сейф. Конечно же, имя последнего майнера будет зафиксировано в финансово-экономической истории.

Одновременно заметим, что методологические студии Чарльза Уилбера и Роберта Харрисона призваны показать способ «моделирования картины», «рассказывание историй», что не является уничижительным, но предполагает, как описание картины в правовом, так и в экономическом смыслах, что характерно для большинства работ по социальным наукам. В самом деле, поисковое истолкование совместимо с юридическим изучением, которое охватывает конкретный образец» [6].

Но вернемся к цифрам. В обороте находится всего 24,66\% намайненных ВТС. Экстраполируя этот результат на число оставшихся не эмитированных еще монет, можно утверждать, что в оборот будет введено всего ок.1 млн. монет. Оставив в стороне темп процесса утери ВТС, надо сказать, что к 2036 году, «на руках» как физических, так и юридических лиц будет находиться несколько менее, чем 5 млн. монет. При сегодняшнем курсе капитализация составит \$32222500000. Как видно, сама криптовалюта ВТС не может представлять какую бы ни было опасность инфляци- 
онного плана для доллара США при нынешней политике Федерального резерва, при которой регулятор сам санирует денежное обращение, изымая из оборота $\$ 50$ млрд. ежемесячно, что следует из заявлений комитета по открытым рынкам и Джерома Пауэлла.

В этой связи, пропажа, причем физическая в полном смысле этого слова 17 млн. криптомонет, унесших с собой $\$ 109565000000$ млрд., может оказать поддержку монетарным властям США.

Ценность классического Bitcoin всегда будет расти. Вместе с тем, прообраз денецетрлиовазнных реестров - мировая валютная система, выступающая формой организации международных расчетов, где SWIFT - информационная основа ее [7].

Для рядового потребителя Bitcoin, эмиссия которого прекратится в 2140 году, кажется сейчас преходящей ценностью, в отношении которой может осуществляться правопреемство. Таким образом, Bitcoin становится наследством премиум-класса, роскошью и финансовым сюрпризом для наследника [8].

Согласно количественной теории денег, количество денег в обращении должно соответствовать величине ВВП в текущих реальных ценах. Монетизация экономики - степень ее насыщенности национальными деньгами и прочими ликвидными активами, регулируется центральными банками [9]. В том случае, если количество денег в обращении становится больше суммы, вытекающей из экономических законов и отслеживаемой регулятором, как результат работы печатного станка или как последствие внешних взбросов денег, то деньги теряют по- купательную силу и наступает инфляция, гиперинфляция. Так было в 90-е годы в Югославии, а сейчас в Венесуэле, что является ярким проявлением инфляции, как следствия вздутия «денежной массы». (Не путать с «пузырем»).

В условиях нынешнего кризиса в Венесуэле, основной проблемой которой была и остается гиперинфляция, правительство ввело токены двух конкурирующих номиналов - PetroDollar (XPD) и Petro (PTR), в качестве фиатных денег, привязав их к нефти. С точки зрения теории денег, это денежная реформа нуллификационного плана, обеспечиваемая государством. Денежные власти Венесуэлы в попытке обойти санкции США добились пока немного. Очевидно, что следовало бы обратить больше внимания на опыт лежащей южнее Аргентины, в то время как El Petro, скорее всего, не решит экономические проблемы президента Венесуэлы Николаса Мадуро, хотя на нефть санкции наложены в меньшей степени, чем на личные активы Н. Мадуро [10].

В заключении венесуэльского сюжета стоит отметить, что только ограничение эмиссии токенов, ставшими фиатными деньгами, позволит Венесуэле преодолеть инфляцию, как феномен экономической жизни в Венесуэле.

Но если в Венесуэле две конкурирующие валюты не носят собственно характера криптовалюты, то в Белоруссии - талер, введенный декретом № 8 «О развитии цифровой экономики» [12], Президентом Республики Беларусь А.Г. Лукашенко - реальная криптовалюта. Поскольку она привязана к белорусскому рублю, то инфляциировать она будет вместе с ним, а это явится

\section{Venezuela's Out of Control Inflation \\ Consumer prices are forecast to jump 2,349.3\% in 2018 \\ IMF Venezuela inflation projection}

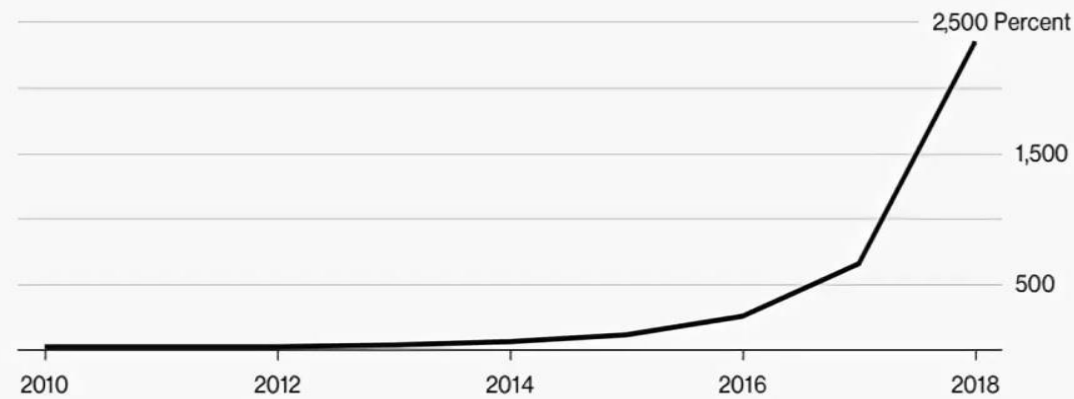

2010

2012

2014

2016

2018

Source: International Monetary Fund World Economic Outlook. 2010-2015 figures from April report, 2016-2018 figures from October report 
дополнительным стимулом для денежных властей Минска осуществлять усиленный мониторинг национального денежного обращения. В противном случае идея криптовалюты будет похоронена, а авторитет властей будет уже не поднять.

Следует иметь в виду, что допуск талера в платежную систему и внутреннее денежное обращение Белоруссии может отнять долю рынка у собственного «зайчика», что, впрочем, относится к компетенции монетарных властей Белоруссии, ведь речь идет уже об агрегатном состоянии денежного обращения.

Вместе с этим, нельзя не отметить, что попытки иностранных, прежде всего, российских и казахстанских союзников по Евразийскому экономическому сообществу, прикупить талер со спекулятивным контекстом, может представлять угрозу экономической безопасности Белоруссии, пожалуй, лишь в теоретическом смысле. Ввиду того, что алгоритмический форк этой валюты имеет строго заданное число монет-талеров - 23 млн. 333 тыс.

Вышесказанное, впрочем, не умаляет достоинств белорусского талера ввиду привлечения инвестиций в оный, чего не происходит в Венесуэле, со стороны белорусской диаспоры в России и из дальнего зарубежья. В целом, как совсем недавно заметил Алан Гриспан: «Для бизнеса трансграничные транзакции могут быть осложнены юридическими рисками и изменчивым обменным курсом, но, как правило, это трудности, не связанные с большинством нормальных бизнес-рисков» [13]. В экономической литературе нашло отражение направление изучения национальных сбережений, куда входят и амортизационные отчисления инвестиций в развитие основного и человеческого капитала [14]. В.И. Маевский, выделяя две стороны движения денег в процессе кругооборота основного капитала [15], пишет о том, что меньшая, но наиболее «неповоротливая» часть этих денег, а именно амортизационные деньги нуждается в финансовых посредниках-банках с той лишь целью, чтобы эти посредники могли бы их аккумулировать и инвестировать.

Генерация амортизационных средств происходит, согласно исследованию, в процессе кругооборота капитала выступая в роли инфраструктурной оболочки, полезность которой не отмечена еще финансовым рынком, когда смарт-контракты еще не поучили должного рас- пространения [16].

Приведенная аналогия достаточно отдаленна, хотя и, скажем откровенно, достаточно чувствительна, однако применяя познавательный инструментарий, может вывести научный поиск на уровень понимания некоторых инновационных процессов и явлений, такого типа как критовалюта, когда оборот тех или иных крипто монет происходит на основе трастовых транзакций.

Выше мы упоминали о двух типах криптовалют, имеющих детерминированный потенциал эмиссии, а также с открытым «проспектом эмиссии». Как видно из изложенного, инфляция криптовалюты с ограниченным режимом эмиссии возможна только в связи с материнской валютой, тогда как криптовалюта второго типа вполне может быть подвержена инфляции. Последнее нуждается в самостоятельным определении и выходит за рамки данной работы. Заметим, наконец, что появление множества иных криптовалют в известной степени уже есть проявление инфляции данного типа денежного инструмента.

Вместе с тем, появление все большего и большего числа криптовалют при первом приближении не делает проблему «вздутой», благодаря нормам, закрепленным действующим законодательством и обреченным форкам, интересных, разве что, их создателям. Однако появление новых и новых форков может увеличить потребление электроэнергии и задействовать простаивающие производственные, да и интеллектуальные мощности.

Представляется, что чем больше будет криптовалют по номиналу-названию, тем меньшую угрозу инфляции они будут представлять.

Процесс дедолларизации известен по 90-м годам в России, когда расчеты между участниками рынка производились в иностранной валюте. В частности, расчеты за недвижимость производились в долларах США, что в условиях высокой волатильности курса было актуальным. В обращении, таким образом, находились, как доллары США в наличной форме, так и рубли фиксированного курса по данным регулятора на дату соответствующих транзакций.

Единственным средством тогда и сейчас было укрепление курса валюты рубля, а также некоторые административные и пропагандистские меры, рост цены на черное золото. Однако тогда в России мало кто задумывался о том, что доллар инфляциировал с темпом в 2\% в год [17]. 
И этот процесс аналогичен рассматриваемому здесь аспекту.

Соответственно привязка криптовалюты к курсу той или иной валюты сделает ее курс волатильным, и она потерпит все невзгоды падающей национальной валюты. Сейчас вложения в криптовалюты - не спасение средств, а разве что инвестиции, а также престижность. Последнее наглядно демонстрируется примерами из экономической истории, когда средства ввиду узости товарного рынка вкладывались в престижные ценности - посуду, произведения искусства, зарубежную собственность, оружие и Т.п.

Потому дедолларизация объективно препятствует введению криптовалюты в какой бы то ни было форме в Российской Федерации, если только это не связано с каким-нибудь подпольным или игорным бизнесом. И это не оговорка. Как известно, участники игр делают ставки с помощью фишек, купленных ими у брокеров за деньги, играя в рулетку. Эти условные денежные знаки (счетные по своей сути), используемые только внутри помещения игрового зала, символизируют стоимость для получения выигрыша в игре - рулетку, однако в любой момент могут быть обменены на деньги.

Выше описаны свойства так называемых «счетных денег». К. Маркс обращал внимание на многочисленные исторические примеры такой moneta imaginaria: «...деньги как счетные деньги могут вообще существовать лишь идеально, в то время как действительно существующие деньги вычеканены по совершенно иному масштабу». Все приведенные примеры показывают, что законная платежная сила денег не по номиналу, а по курсу есть широко известное явление в истории денежного обращения [18]. И хотя приведенная сентенция небесспорна с точки зрения денежной теории ввиду того, что крпитовалюты в то время не существовало, она позволяет непрофессиональным участникам рынка ценных бумаг и криптовалюты сориентироваться в сложных теоретических посылках фрагмента денежной теории.

На самом деле, положение о счетных деньгах не расходится с нюансами количественной теории денег, когда при развивающемся исследовании теории крупнейший представитель чикагской экономической школы Милтон Фридман просто не назвал данный фрагмент субинститута денег [19].
С точки зрения практики денежного обращения, как сказала еще в начале года директор-распорядитель МВФ Кристин Лагард, криптовалюты следует рассматривать как финансовые инструменты, в том числе и производные. По мнению авторов, данное определение не только не сковывает участников рынка, но и наоборот позволяет теоретикам включить криптовалюты в правовое поле и успешно развивать те или иные положения.

После опубликования перечня поручений Президента РФ по итогам совещания по вопросу использования цифровых технологий в финансовой сфере [20], Государственная Дума в первом чтении приняла Проект Федерального закона N419059-7 «О цифровых финансовых активах» [21]. В исходной редакции законопроект нормативно обозначал два вида цифровых финансовых активов: криптовалюты и токены, однако впоследствии все нормы о криптовалюте были исключены из текста законопроекта [22]. При этом происходит инфляция издержек со стороны майнеров и пользователей криптовалют к законодательной власти, которая не сумела при наличии поручений Президента организовать законопослушных граждан и других пользователей криптовалют в рамках законодательного централизованного процесса обращения цифровых денег, на которых основаны преимущества новой экономики [23], что находит противоречие со стремлением властей поставить Россию на путь цифровой экономики.

Изложенное позволяет прийти к заключению о том, что такие явления, как инфляция, исходят от природы той или иной «породы» денег, а ведь известно, что агрегаты меняют стоимость по отношению друг к другу. Кризисы ликвидности бывают, что есть кризис банальной наличности. И регулятору вряд ли нужны лишние проблемы когда, допустив в обслуживание денежного оборота криптовалюты, ему в случае кризиса придется спасать владельцев обесценившихся денег, предоставляя реальные рубли и теряя при этом сеньоражный доход, вспомним, например, валютных ипотечников, что есть одно из проявлений - следствий валютного кризиса 2014 года.

Бумажные деньги появились в 10 веке в Китае. Когда об этом в Европе рассказал Марко Поло, его подняли на смех. И до недавнего времени никто и предположить не мог, что человечество сделает первый шаг к криптовалюте. 


\section{Библиографический список}

1. Абалкин Л.И. Информационные системы банков / [Абалкин Л. И. и др.] Москва.:1995. С.25.

2. bitcoinblockhalf.com

3. https://ru.investing.com/quotes/us-dollar-index; WWW://WSJEconomy08112018.

4. Оценивая восприятие инфляции домашними хозяйствами США, авторы одного из последних аналитических докладов Федерального резерва, замечают, что официально измеренный уровень инфляции был, в самом деле, низким «в 2015 и 2016 годах, поскольку она /инфляция - авт./, помимо прочего, отражала резкое снижение мировых цен на нефть, начавшееся в середине 2014 г. Тем не менее, инфляция заметно выросла в 2017 году и в первой половине 2018 года, а медианное краткосрочное восприятие также дрейфовало вверх, хотя и с задержкой». См.: https://www.federalreserve.gov/econres/feds/files/2018073pap.pdf.

5. https://cryptostate.ru/instrukcii/skolko-vsego-btc

6. Law and Social Economics. Essays in Ehical Values for Theory, Practice, and Policy. Edited byMarkD.White. New York, 2015, p.61-63.

7. Финансы, кредит и валютные отношения зарубежных стран / А.В. Бойченко, С.К. Дубинин; МГУ им. М.В. Ломоносова, Экон. фак., 1989, с.69; Абалкин Л.И.. Экономическая реформа: зигзаги судьбы и уроки на будущее. М.: ИЭ, 1995, с.25;

8. Последнее, впрочем, нуждается в самостоятельном изучении. См.: Максуров А.А. Криптовалюты и правовое регулирование их обращения: монография / М.: Дашков и Кㅇ 2018. - С.37; Коржова И.В. «Правовое регулирование криптовалюты в Российской Федерации» 2018 г.: Дипломные, курсовые работы по коммерческому праву/ КонсультантПлюс - студенту и преподавателю [Электронный ресурс]. M.: MГУ, 2018. URL: http://www.consultant.ru/edu/student/nauka/commerce/;

9. Проблема монетизации экономики России поднимались в пероид первого бума цен на углеводороды Г.И. Ясиным. См.: Ясин Г.И. Нефть, цены и инфляция // ВЭ. 2005. № 9, с.11 Постепенное, выверенное, но не плавное увеличение денежной массы в нынешних условиях с потенциалом введения критовалюты следует учитывать монетарным властям ввиду изменения соотношения агрегатов денежного обращения. См.: Фрилман М., Указ.соч., с.144-145;

10. https://www.rbc.ru/newspaper/2018/02/21/5a8c4b7c9a79471f63a3b56c.

11. https://investfuture.ru/news/id/mvf-jdet-inflyaciyu-v-venesuele-na-urovne-2300.

12. Декрет № 8 от 21 декабря 2017 г. «О развитии цифровой экономики», подписанный Президентом Республики Беларусь Александр Лукашенко.

13. Greenspan Alan. Balance of payments imbalances / Alan Greenspan Washington: Per Jacobsson found., 2007 P.4.

14. Гринспан А. Карта и территория. Риск, проблема человесчекого разхвития М.: Альпина Публигер. Перс. А нгл., 2015, с.93.

15. Маевский В.И. Воспроизводство основного капитала и экономическая теория О воспроизводстве основного капитала в стоимостном аспекте // Вопросы экономики, 2010, № 3., с.84.

16. Oliver Hart, Moore John. Contracts as reference points // The Quarterly journal of economics. 2008. Vol. CXXIII February 2008. Issue 1. P.1-48.

17. Velde Francois $R$. How do we measure inflation? // ChicagoFed Letter. ESSAYS ON ISSUES THE FEDERAL RESERVE BANK OF CHICAGO. 2015.NUMBER347, p.1-3.

18. Луни, Л.А. Деньги и денежные обязательства в гражданском праве. Москва. 1999. 351, [1] с.; 21 см. Классика российской цивилистики / Моск. гос. ун-т им. М.В. Ломоносова. Каф. гражд. права Юрид. фак.). 2004. Москва. С.281.

19. Фридман М. Если бы деньги заговорили. 1998. С.30, п.8.

20. http://kremlin.ru/acts/assignments/orders/55899.

21. Проект Федерального закона N419059-7 «О цифровых финансовых активах» (ред., внесенная в ГД ФС РФ, текст по состоянию на 20.03.2018).

22. https://iz.ru/790431/.

23. Вайпан В.А. Основы правового регулирования цифровой экономики // Право и экономика. 2018. № 11. С.5. 